\title{
Brief
}

Communications

\section{Changes in $\$ 100 \beta$ protein levels in cerebrospinal fluid after thoracoabdominal aortic operations}

\author{
Takashi Kunihara, MD, PhD, Norihiko Shiiya, MD, PhD, and Keishu Yasuda, MD, PhD, Sapporo, Japan
}

See related editorial on page 853 .

From the Department of Cardiovascular Surgery, Hokkaido University School of Medicine, Sapporo, Japan.

Received for publication Nov 2, 2000 accepted for publication Feb 12, 2001.

Address for reprints: Takashi Kunihara, MD, Department of Cardiovascular Surgery, Hokkaido University School of Medicine, N14, W5, Kita-ku, Sapporo, Japan 060-8648 (E-mail: kunihara@med.hokudai.ac.jp).

J Thorac Cardiovasc Surg 2001;122:1019-20

Copyright (C) 2001 by The American Association for Thoracic Surgery

$0022-5223 / 2001 \$ 35.00+0 \quad \mathbf{1 2 / 5 4 / 1 1 5 1 5 1}$ doi:10.1067/mtc.2001.115151

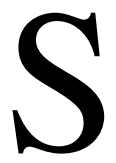

$100 \beta$ protein, which is found at a high concentration in glial and Schwann cells, is considered to be a promising biochemical marker of spinal cord injury (SCI). ${ }^{1}$ However, serum S100 $\beta$ levels after cardiopulmonary bypass (CPB) are influenced by extracerebral contamination, ${ }^{2}$ increased permeability of the blood-brain barrier, and impaired renal function. ${ }^{3}$ Because S100 $\beta$ levels in the cerebrospinal fluid (CSF) are unlikely to be affected by these responses to CPB, and CSF samples can be collected when CSF drainage is used, it seems reasonable to measure them as a marker of SCI. The purpose of this study is to elucidate the alterations of S100 $\beta$ levels in the CSF and the serum up to 72 hours postoperatively and to correlate them with the neurologic outcome in patients undergoing thoracoabdominal aortic operations.

\section{Methods}

A total of 23 patients (12 men and 11 women; mean age, $64 \pm 14$ years) undergoing prosthetic replacement of the descending thoracic $(n=6)$ or thoracoabdominal aorta $(n=17)$ and CSF drainage between April 1997 and February 2000 were enrolled in this study. The medical ethical committee approved CSF drainage, and all patients gave written informed consent. Patients with postoperative renal insufficiency were excluded. The cause of disease was dissection in 8 patients and nondissection degenerative disease in 15 patients. Two patients underwent nonelective operations.

Partial femorofemoral CPB was used in 18 patients who were divided into 2 groups with (SCI group, $\mathrm{n}=4$ ) or without (FF group, $\mathrm{n}=14$ ) postoperative SCI. Deep hypothermic total $\mathrm{CPB}$ was used in 5 patients (DH group). The lowest rectal temperature for each adjunct was $34^{\circ} \mathrm{C} \pm 1{ }^{\circ} \mathrm{C}$ and $20^{\circ} \mathrm{C} \pm 2{ }^{\circ} \mathrm{C}$. Characteristics of each group were comparable, except that patients with dissection were more prevalent $(P=.0321)$ and duration of $\mathrm{CPB}$ was significantly longer $(P=.0024)$ in the DH group. A cardiotomy sucker was used in all but 4 patients in the FF group. A centrifugal cell-salvage device was used in all patients, and an arterial filter was not used.

CSF drainage was started just after the induction of anesthesia and was continued until 72 hours after the operation. CSF was allowed to freely drain if CSF pressure exceeded $13 \mathrm{~cm}$ $\mathrm{H}_{2} \mathrm{O}$. The CSF and arterial blood were collected at just before the operation and at $0,6,12,18$, 24,48 , and 72 hours after the operation. S100 $\beta$ levels were measured with an immunoradiometric assay kit (Sangtec Medical, Bromma, Sweden). The minimum detectable level was 0.2 $\mu \mathrm{g} / \mathrm{L}$. All values are expressed as means \pm standard deviation.

\section{Results}

There were no hospital deaths. Postoperative SCI occurred in 4 patients ( 2 with paraplegia and 2 with paraparesis) with nondissecting degenerative aneurysms.

CSF S100 $\beta$ levels in the SCI group showed a dramatic increase from 6 hours after the operation compared with the other 2 groups $(P<.0001$ vs FF group and $P<.01$ vs DH group by repeated-measures analysis of variance) and reached their peak at 48 postoperative hours $(289 \pm 454 \mu \mathrm{g} / \mathrm{L}$, Figure 1$)$. From 18 to 72 hours postoperatively, both paraplegic patients had higher CSF S100 $\beta$ levels than patients with paraparesis. 


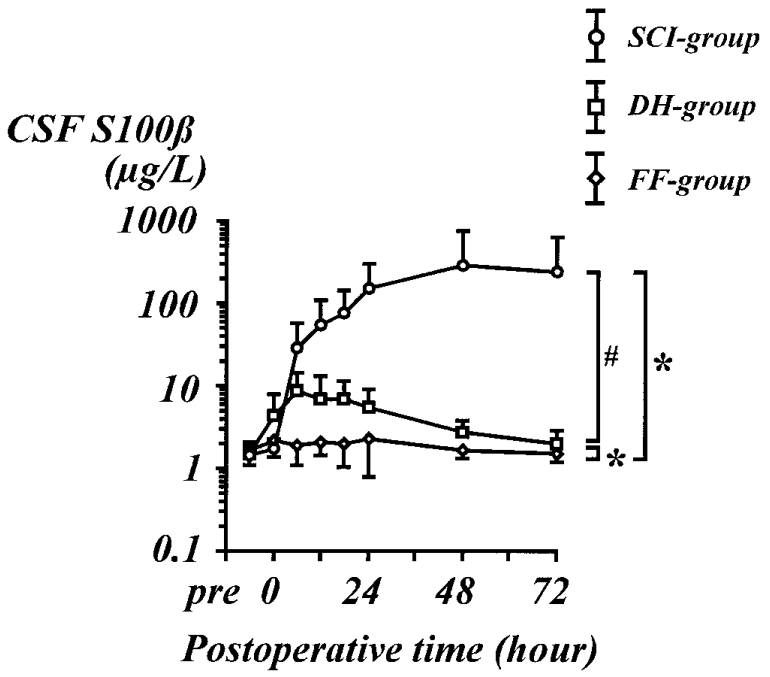

Figure 1. Time course of $S-100 \beta$ protein levels in the CSF. ${ }^{*} P<.0001$ and $\# P<.01$ with repeated-measures analysis of variance.

CSF S100 $\beta$ levels in the DH group showed a small peak 6 hours after the operation $(8.8 \pm 5.7 \mu \mathrm{g} / \mathrm{L})$, whereas those in the FF group did not have an apparent peak. There was a significant difference between them $(P<.0001)$.

Mean serum S100 $\beta$ levels were less than $1.5 \mu \mathrm{g} / \mathrm{L}$ and reached their peak just after the operation in each group (Figure 2). In the SCI group serum $\mathrm{S} 100 \beta$ levels showed a second and more pronounced peak at 24 hours postoperatively $(1.3 \pm 1.4 \mu \mathrm{g} / \mathrm{L})$.

\section{Discussion}

Although we used only a small cohort, results of the present study clearly demonstrated that CSF S $100 \beta$ levels were significantly correlated with SCI, and those in the SCI group peaked 48 hours after thoracoabdominal aortic operations. Another important finding is that CSF levels seem more reliable than serum levels because CSF S100 $\beta$ levels of the SCI group were from 10- to 100-fold higher than serum S100 $\beta$ levels. These results not only confirmed those of a previous report by Van Dongen and colleagues ${ }^{1}$ but also disclosed alterations of CSF S100 $\beta$ levels after 24 postoperative hours with the addition of statistical power. Although we could treat potential SCI with a novel rapid assay, ${ }^{4}$ the value of CSF S100 $\beta$ levels to predict SCI earlier than clinical diagnosis remains to be investigated in the further study. Higher CSF S100 $\beta$ levels in the DH group may indicate more pronounced inflammatory response related to CPB and reduced collateral circulation of the spinal cord during open distal anastomosis. Larger studies will be required to

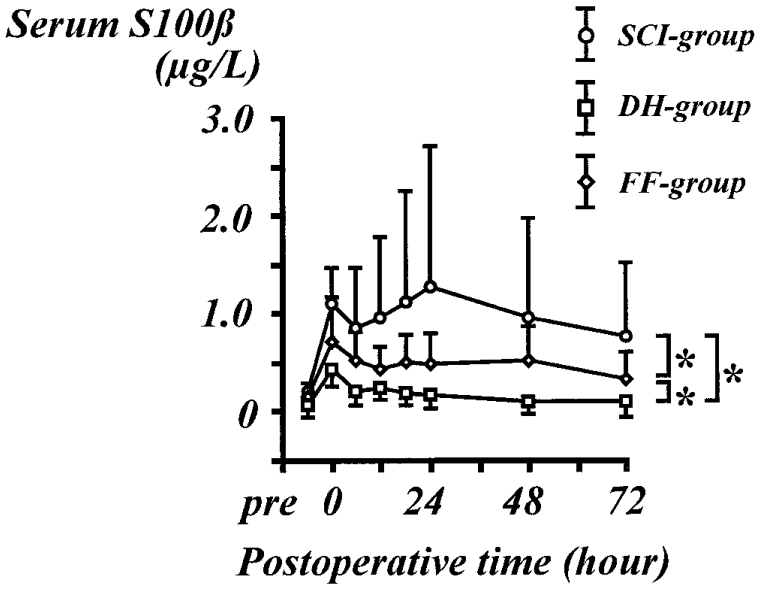

Figure 2. Time course of $S-100 \beta$ protein levels in the serum. ${ }^{*} \boldsymbol{P}<$ .0001 with repeated-measures analysis of variance.

confirm this finding. In addition to augmentation of spinal cord perfusion pressure, removal of S100 $\beta$ from the CSF may be another possible advantage of prolonged CSF drainage to prevent delayed aggravation of SCI because S100 $\beta$ may induce apoptotic neuronal death in high concentrations. ${ }^{5}$ In conclusion, CSF S100 $\beta$ level seem to be a sensitive biochemical marker of SCI.

We thank Toshiyuki Onishi, MD, Central Institute of Radioisotope Science, and Kenji Fujieda, MD, Department of Pediatrics, for help in measurement of S100 $\beta$ levels.

\section{References}

1. van Dongen EP, Ter Beek HT, Boezeman EH, Schepens MA, Langemeijer HJ, Aarts LP. Normal serum concentrations of S-100 protein and changes in cerebrospinal fluid concentrations of S-100 protein during and after thoracoabdominal aortic aneurysm surgery: Is S-100 protein a biochemical marker of clinical value in detecting spinal cord ischemia? J Vasc Surg. 1998;27:344-6.

2. Jönsson H, Johnsson P, Alling C, Bäckström M, Bergh C, Blomquist S. S100 $\beta$ after coronary artery surgery: release pattern, source of contamination, and relation to neuropsychological outcome. Ann Thorac Surg. 1999;68:2202-8.

3. Hammon JW Jr, Stump D. Commentary: biochemical markers of brain injury after cardiac surgery. J Thorac Cardiovasc Surg. 2000;119:130-1.

4. Ettinger A, Laumark AB, Ostroff RM, et al. A new optical immunoassay for detection of S-100B protein in whole blood. Ann Thorac Surg. 1999;68:2196-201.

5. Hu J, Van Eldik LJ. S100 $\beta$ induces apoptotic cell death in cultured astrocytes via a nitric oxide-dependent pathway. Biochim Biophys Acta. 1996;1313:239-45. 